\title{
PAPERS
}

\section{$\beta$ Amyloid protein deposition in the brain after severe head injury: implications for the pathogenesis of Alzheimer's disease}

\author{
G W Roberts, S M Gentleman, A Lynch, L Murray, M Landon, D I Graham
}

\begin{abstract}
In a recent preliminary study it was reported that a severe head injury resulted in the deposition of $\beta$ amyloid protein ( $\beta A P)$ in the cortical ribbon of $30 \%$ of patients who survived for less than two weeks. Multiple cortical areas have now been examined from 152 patients (age range 8 weeks- 81 years) after a severe head injury with a survival time of between four hours and $2 \cdot 5$ years. This series was compared with a group of 44 neurologically normal controls (age range 51 to 80 years). Immunostaining with an antibody to $\beta A P$ confirmed the original findings that $30 \%$ of cases of head injury have $\beta A P$ deposits in one or more cortical areas. Increasing age seemed to accentuate the extent of $\boldsymbol{\beta A P}$ deposition and potential correlations with other pathological changes associated with head injury were also investigated. In addition, $\beta$ amyloid precursor protein $(B A P P)$ immunoreactivity was increased in the perikarya of neurons in the vicinity of $\beta A P$ deposits. The data from this study support proposals that increased expression of $\beta A P P$ is part of an acute phase response to neuronal injury in the human brain, that extensive overexpression of $\beta A P P$ can lead to deposition of $\beta A P$ and the initiation of an Alzheimer diseasetype process within days, and that head injury may be an important aetiological factor in Alzheimer's disease.
\end{abstract}

$(\mathcal{F}$ Neurol Neurosurg Psychiatry 1994;57:419-425)

Head injury is an everyday event that results in over 100000 hospital admissions a year in the United Kingdom. ${ }^{1}$ Clinical attention is focused on the crisis management of the patient in the 48 hours immediately after injury. About a third of the patients (30 000 a year in the United Kingdom) who survive the initial injury experience long term sequelae that range from permanent debilitating neurological deficits to more subtle psychiatric symptoms. ${ }^{12}$ The acute neuropathological consequences of closed head injury have been described in some detail and include contusional injury, ${ }^{3}$ diffuse axonal injury, ${ }^{4}$ hypoxic or ischaemic damage, ${ }^{5}$ and raised intracranial pressure. ${ }^{6}$ There is a considerable body of data indicating that head injury is linked to a chronic neurodegenerative process, although in most studies the pathological basis of this process is unknown. This general lack of insight linking cause and effect has been dispelled in studies that have investigated the molecular pathology of the punch drunk syndrome in boxers (dementia pugilistica).

The repeated blows to the head experienced by professional boxers are associated with a well characterised, progressive dementing syndrome. ${ }^{7}$ The disease is characterised neuropathologically by a cavum septum, neuronal loss, cerebellar scarring, and intense neurofibrillary tangle formation in the cortex. ${ }^{8}$

Dementia pugilistica had been regarded as a separate diagnostic entity from other common dementias because the cortex showed no appreciable plaque formation, as defined by silver and Congo red histochemistry. ${ }^{8} \mathrm{We}$ have shown this to be erroneous. The brains of boxers with dementia pugilistica contain large numbers of $\beta$ amyloid protein $(\beta A P)$ containing diffuse plaques. ${ }^{9}$ Furthermore we have also shown that the tangles in dementia pugilistica are ubiquitinated, ${ }^{10}$ occasionally decorated with $\beta \mathrm{AP},{ }^{11}$ and are immunologically indistinguishable from those seen in Alzheimer's disease. ${ }^{12} \mathrm{We}$ have argued that a preponderance of diffuse plaques such as those seen in the cortex in dementia pugilistica might indicate a long term consequence of head injury..$^{13}$ Similar patterns of molecular neuropathology have been described in other trauma-related cases of dementia-a 33 year old man with a single incidence of head injury ${ }^{13}$ and an elderly woman with a history of domestic violence and repeated blows to the head. ${ }^{14}$ We have also reported the presence of $\beta A P$ deposits in the cortex of $30 \%$ of patients dying of a single incidence of severe head injury. ${ }^{15}$

Together these observations give a considerable insight into the molecular events that underlie the chronic effects of head injury. They provide powerful support for the proposal that head injury could, in some instances, trigger the process of Alzheimer's disease; an association that has been supported by epidemiological ${ }^{16-19}$ and neuropathological studies. ${ }^{12} 19$ If such interpretations are correct they represent an important advance in our understanding of how environmental factors (commonly believed to be involved in over $80 \%$ of cases of Alzheimer's 
disease) trigger or modulate the central pathological event in Alzheimer's disease-the overexpression and metabolism of the $\beta$ amyloid precursor protein ( $\beta \mathrm{APP}$ ) to $\beta \mathrm{AP} .{ }^{20}{ }^{21}$

Our preliminary data reporting the presence of $\beta A P$ deposits in the cortex of patients dying within two weeks of severe head injury ${ }^{15}$ are clearly central pieces of evidence in the study of the environmental determinants of Alzheimer's disease. It has been argued, however, that our findings on the punch drunk syndrome and post-traumatic Alzheimer's disease have been limited to extremes of the clinicopathological spectrum and this is a cogent criticism. Also, it has been suggested that our observations on patients with severe head injury might be an artefact related either to the age of the patients or an accumulation of $\beta \mathrm{AP}$ in macrophages surrounding the vascular lesions found in these patients.

Thus to test our hypothesis that head injury can trigger $\beta$ AP deposition in the cortex we examined the brains of over 150 patients who died within weeks of severe head injury and compared their pattern of pathological stigmata with that of a group of 44 well characterised age matched controls.

\section{Materials and methods} PATIENTS

A total of 152 patients (109 males) with severe head injury were studied (age range 8 weeks to 85 years) with survival times ranging from four hours to 2.5 years. Most of the injuries were attributable to road traffic accidents or to falls.

A full postmortem examination was undertaken in every case. The brains were suspended in $10 \%$ formol saline for three to four weeks, before being dissected in a standard fashion: the cerebral hemispheres were sliced in the coronal plane, the cerebellum at right angles to the folia, and the brainstem horizontally. Comprehensive histological studies were undertaken in each case. In 116 cases (those processed before 1990) a comprehensive data set was also available that contained assessments of the amount of contusional injury, ${ }^{3}$ the severity of any diffuse axonal injury, ${ }^{4}$ the severity of any ischaemic damage, ${ }^{5}$ and whether the intracranial pressure had been high during life as a result of supratentorial expanding lesions. ${ }^{6}$

Control material was obtained from a large series ( $n=45$, age range 51 to 80 years, 26 male) of patients. None of these patients had evidence of significant head injury or of neurological or psychiatric disease in life. The exclusion of controls with head injury is a significant difference between our study and that of Davies et al. ${ }^{22}$

\section{IMMUNOCYTOCHEMISTRY}

At least two cortical areas (including the whole temporal lobe and parietal cortex) were examined from each case. All sections were pretreated with $80 \%$ formic acid for eight minutes and then incubated overnight with a monoclonal antibody to $\beta \mathrm{AP}(1 / 6 \mathrm{~F} / 3 \mathrm{D})$ at a dilution of $1: 1000$. They were then processed according to a previously described protocol ${ }^{23}$ and counterstained with haematoxylin.

Sections were examined blind and the extent of $\beta$ AP deposition was examined and semiquantitative ratings of the amount of $\beta A P$ deposition were made. The number of deposits were rated using a slightly modified Consortium to Establish a Registry of Alzheimer's Disease (CERAD) protocol. ${ }^{24}$ As originally described this protocol used silver stained sections to assess the numbers of neuritic plaques. The illustrations given in the protocol provide a simple means of accurately conveying an idea of the numbers of plaques in a given area. We have used our immunocytochemical techniques and the CERAD approach to convey an idea of the numbers of $\beta A P$ deposits in our material.

A subseries of cases $(n=11)$ with and without $\beta \mathrm{AP}$ deposits was selected at random to explore the pattern of immunoreactivity exhibited by $\beta$ APP. Immunoreactivity to $\beta$ APP was detected with a well characterised, commercially available monoclonal antibody to the C-terminal of $\beta \mathrm{APP}$ (clone 22C11, Boehringer, dilution 1:20).

\section{Results}

BAP IMMUNOREACTIVITY

When examined microscopically $30 \%$ (46 of $152)$ cases were found to exhibit $\beta$ AP deposits (fig 1). A case was defined as positive for $\beta \mathrm{AP}$ deposition if one or more cortical areas contained a minimum number of deposits equivalent to the rating of "sparse" according to our modification of the CERAD protocol.

In the controls there were no $\beta \mathrm{AP}$ positive patients under the age of 60 . Patients between the ages of 60 and 80 showed positivity rates of over $50 \%$. The proportion of cases of head injury with $\beta \mathrm{AP}$ deposits was greater than that seen in controls (fig 2). Deposition of $\beta A P$ was not seen in patients with head injuries under the age of 10 years. The youngest positive cases was only 10 years old and some $20 \%$ of cases in their teens, 20 s and 30 s showed limited $\beta \mathrm{AP}$ deposition. Increasing age was associated with increasing rates of positivity (fig 2). As in our previous study the pattern and local amounts of $\beta A P$ deposits differed from case to case. Of the regions examined, the medial temporal cortex was the area most often affected.

The frequency and extent of $\beta \mathrm{AP}$ deposits increased dramatically over 60 years of age in both the controls and the subjects with head injuries. The positivity rate for $\beta \mathrm{AP}$ deposition in these older patients, although reaching over $50 \%$, was still significantly less than the $70 \%$ seen in the patients with head injuries of the same age (fig 2). In addition there were fewer $\beta$ AP deposits in controls than in patients with head injuries of the same age.

\section{$\beta$ APP IMMUNOREACTIVITY}

A total of 11 cases of head injury (age range $18-65$, six $\beta A P$ positive and five negative) were examined with the $\beta A P P$ antibody. A 


\section{Figure $1 \quad \beta A P$ \\ immunoreactive deposits in the frontal cortex of a 46 year old man who survived for 10 days after injury $(A, B) ; \beta A P P$ \\ immunoreactivity in \\ cortical perikarya in an 18 year old man who survived for five days $(C)$; and in damaged axons in a 60 year old man who survived for 24 hours (D). Scale bars $=200 \mu \mathrm{m}$ for $A$ and $100 \mu \mathrm{m}$ for $B, C$, and $D$.}
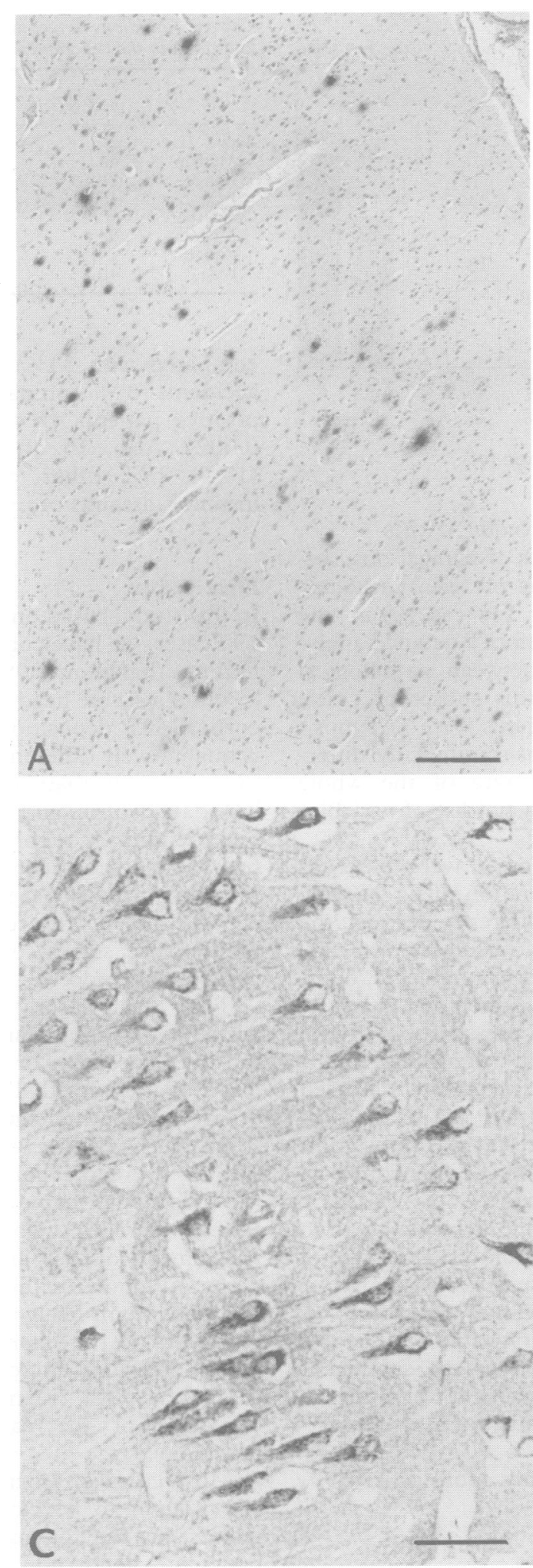

generalised increase in $\beta \mathrm{APP}$ immunoreactivity was evident in all the cases examined, particularly in the neurons of cortical layers III and IV (fig 1). $\beta$ APP was also present in isolated structures resembling dystrophic neurites and within dystrophic neurites associated with neuritic plaque structures. These plaque structures also contained the central $\beta$ AP immunoreactive deposits that typify neuritic, classical, or senile plaques. This type of plaque was, however, restricted to the oldest cases.

$\beta A P P$ immunoreactivity was pronounced in
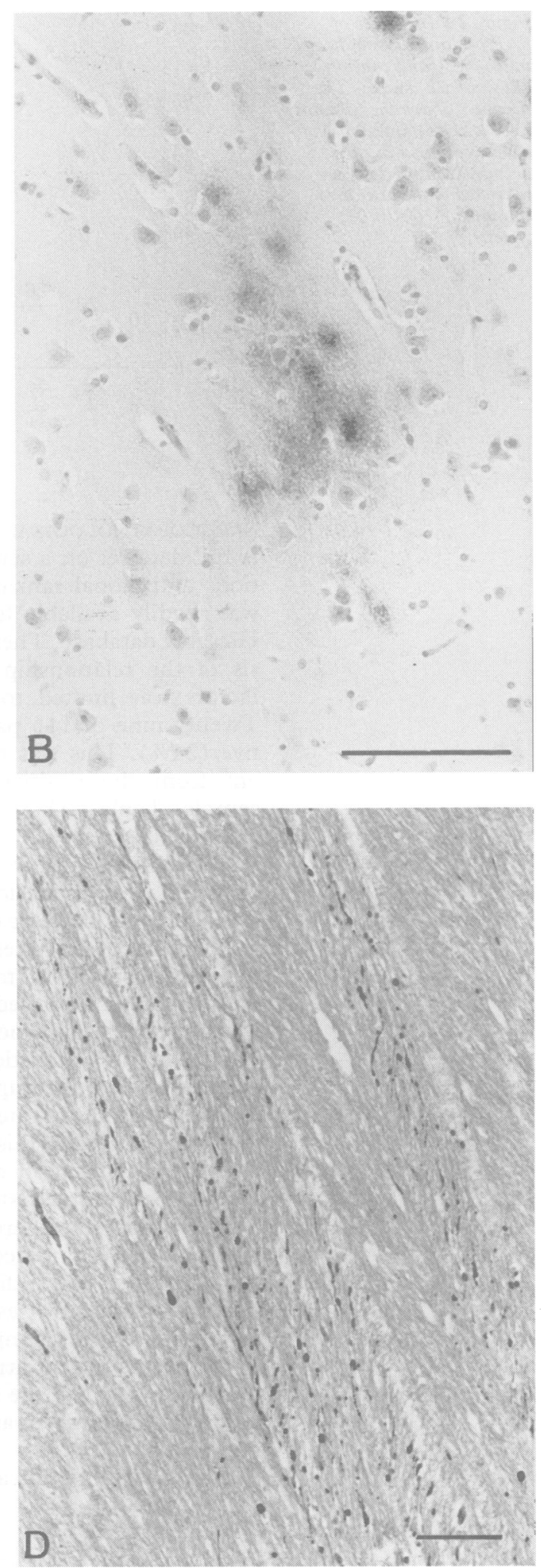

the damaged axons of the white matter (fig 1). Immunoreactivity was noted both proximal and distal to the site of damage. The pattern of $\beta$ APP immunoreactivity matches with the pattern of diffuse axonal injury visualised after silver impregnation. ${ }^{4}$

The increased neuronal $\beta$ APP immunoreactivity was a more widespread phenomenon than the deposition of $\beta A P$. Increased numbers of $\beta$ APP immunoreactive neurons were often present, however, in the immediate vicinity of $\beta$ AP deposits. 
Figure 2 Incidence of $B A P$ positive cases of head injury $(\square)$ and controls (1) in each decade. The numbers above the columns refer to the total number of cases examined in each decade. Control data are restricted to the last three $\chi^{2}$ test). columns $\left({ }^{*} p<0.01\right.$;

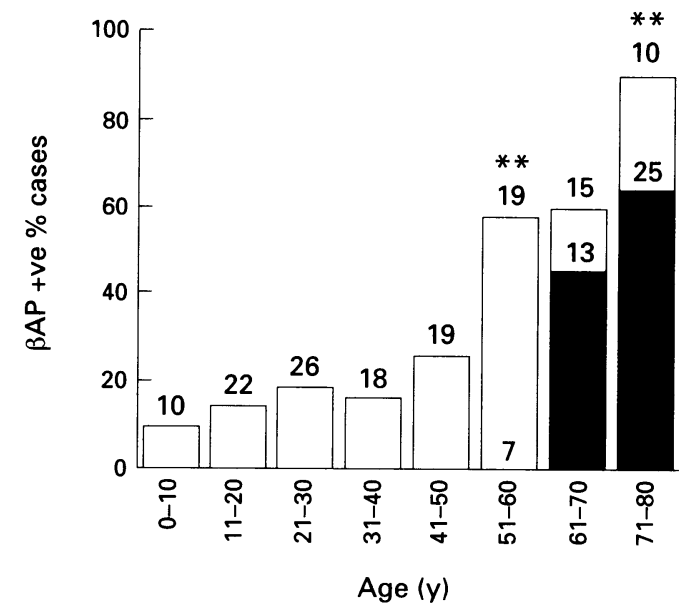

CLINICOPATHOLOGICAL CORRELATIONS

A full data set on a series of clinical observations and global rankings of brain pathology was readily available for 116 cases from the Glasgow database. Therefore a detailed analysis of the relationship between pathological factors was limited to this subset of cases. Twenty nine of 116 patients were $\beta A P$ positive $(24 \%)$. This was not significantly different from the positivity rate of the whole sample. Table 1 shows a full list of variables examined.

Overall the positive cases were older as expected from a consideration of fig 2 (table 2 ). There was no clear difference between the $\beta \mathrm{AP}$ positive and negative cases for sex, degree of coma on admission (table 2), operated haematoma, raised intracranial pressure, brain swelling, low blood pressure, or survival time. The only statistically significant difference between the groups was in the increased degree of clinically rated hypoxia in the $\beta \mathrm{AP}$ negative group, but this result was not significant after application of the Bonferroni correction for multiple testing.

There was no difference between the two groups when compared for the presence of skull fracture, severe diffuse axonal injury, or neuropathologically assessed moderate or severe hypoxic brain injury (table 1 ). The last result seems to confirm that the significant difference between the groups for clinical rating of hypoxia was an artifact of multiple testing.

There were significantly more falls $(69 \%$

Table 1 Rate of occurrence of clinical features in the two groups

\begin{tabular}{lclc}
\hline & $\begin{array}{l}\beta A P \text { present } \\
\left(p_{1}\right)\end{array}$ & $\begin{array}{l}\beta A P \text { absent } \\
\left(p_{2}\right)\end{array}$ & $\begin{array}{l}p_{2}-p_{1} \text { (95\% CI) } \\
(\%)\end{array}$ \\
\hline $\begin{array}{l}\text { Male } \\
\text { DAI }\end{array}$ & $17 / 29(59)$ & $66 / 87(76)$ & $17(-3$ to 37$)$ \\
Raised ICP & $5 / 18(28)$ & $17 / 68(25)$ & $-3(-26$ to 20$)$ \\
$\begin{array}{l}\text { Hypoxic brain damage } \\
\text { (moderate/severe) }\end{array}$ & $21 / 29(72)$ & $62 / 86(72)$ & $0(-19$ to 18$)$ \\
$\begin{array}{l}\text { Operated intracranial } \\
\text { haematoma }\end{array}$ & $8 / 27(30)$ & $34 / 79(43)$ & $13(-7$ to 34$)$ \\
$\begin{array}{l}\text { Brain swelling } \\
\text { Clinically low BP }\end{array}$ & $14 / 29(24)$ & $24 / 87(28)$ & $4(-15$ to 22$)$ \\
$\begin{array}{l}\text { Clinical signs } \\
\text { of hypoxia }\end{array}$ & $8 / 28(29)$ & $50 / 86(58)$ & $10(-11$ to 31$)$ \\
$\begin{array}{l}\text { Survival time } \\
\quad<24 \text { hours }\end{array}$ & $2 / 29(7)$ & $15 / 76(20)$ & $-9(-28$ to 10$)$ \\
$>72$ hours & $12 / 29(41)$ & $26 / 78(33)$ & $26(13$ to 40$)$ \\
\hline
\end{tabular}

Percentages in parentheses; $95 \% \mathrm{CI}=95 \%$ confidence interval; $\mathrm{DAI}=$ diffuse axonal injury; $\mathrm{ICP}=$ intracranial pressure; $\mathrm{BP}=$ blood pressure.
Table 2 Median, range, and interquartiles (I-Q) for age and coma in the two groups

\begin{tabular}{llll}
\hline & $\beta A P$ present & $\beta A P$ absent & $\begin{array}{l}\text { (95\% CI for } \\
\text { median difference) }\end{array}$ \\
\hline Age: & & & \\
$\quad$ Median & 60 & 26 & (20 to 37) \\
$\quad$ Range & $21-83$ & $0-74$ & \\
I-Q & 46,68 & 17,46 & \\
$\begin{array}{l}\text { Coma score: } \\
\quad \text { Median }\end{array}$ & 6 & 6 & (- 1 to 2$)$ \\
Range & $3-15$ & $3-15$ & \\
I-Q & 4,11 & 4,11 & \\
\hline
\end{tabular}

compared with $34 \%$ ) and fewer road traffic accidents ( $31 \%$ compared to $55 \%$ ) in the $\beta \mathrm{AP}$ positive patients $\left(\chi^{2}=12 \cdot 26\right.$ with $2 \mathrm{df}, \mathrm{p}=$ $0.002)$. Also, 15 of the 87 negative cases (17\%) had other causes of injury (for instance, assaults or unknown).

\section{Discussion}

In this study, based on the data from a total of 197 cases, we have confirmed our preliminary findings that about $30 \%$ of patients dying as a result of a severe head injury show evidence of cortical $\beta \mathrm{AP}$ deposition. The $\beta \mathrm{AP}$ deposition is qualitatively different from and significantly more extensive than anything seen in controls. The data confirm and extend those detailed in our preliminary report and support the proposal that increased expression of $\beta A P P$ is a response to neuronal injury. ${ }^{15}$ In certain susceptible patients this response evolves into the preliminary stages of an Alzheimer type pathological process.

The most clearly identified causes of Alzheimer's disease are genetic and involve the overexpression or altered metabolism of $\beta$ APP. Patients with Down's syndrome inexorably develop the characteristic pathology of Alzheimer's disease-presumably due to a lifelong overexpression of $\beta$ APP arising from the additional copy of chromosome $21 . .^{25}$ Several families with autosomal dominant Alzheimer's disease are now known to have point mutations within the $\beta$ APP gene. ${ }^{26}$ It therefore seems likely that extended periods of increased $\beta \mathrm{APP}$ expression or changes in $\beta A P P$ structure increase the likelihood of generating $\beta \mathrm{AP}$ fragments and subsequent triggering of the cascade of Alzheimer's pathology. ${ }^{20} 27$

Most cases of Alzheimer's disease (80\%) are thought to be caused by environmental factors that may or may not interact with the patients' genotype. ${ }^{21}$ Thyroid problems, maternal age, solvent exposure, aluminium toxicity, and transmissible agents have all been suggested as relevant aetiological determinants. ${ }^{28}$ Head injury is the environmental factor most consistently associated with the disease, however. ${ }^{29}$ Interestingly, head injury also seems to precipitate the onset of Alzheimer's disease in patients with $\beta$ APP gene mutations. In two separate pedigrees with well defined ages of onset a family member with precocious onset (10 years younger than the mean) was found to have a history of significant head injury (J Hardy, personal communication). 
Both the epidemiological evidence (associating head trauma and Alzheimer's disease) ${ }^{18}$ and the neuropathological studies detailing the similarity between dementia pugilistica and Alzheimer's disease, ${ }^{9-12}$ have aroused interest in the relation between response to brain injury and subsequent neurodegeneration. Acceptance of the concept that head injury can act as an environmental precipitant of Alzheimer's disease has been complicated, however, by the lack of a clear understanding of how an event such as head injury, limited in time and place, can relate to or trigger a long term process of neurodegeneration. For example, in the case of some boxers there may be an interval of 35 years between the initiating events and the neuropathological investigation to determine the basis of clinical symptoms. ${ }^{9}$ Thus, whereas evidence from such studies is compelling in terms of reinforcing the causal link between brain injury and an Alzheimer type pathology, it is of limited value in furthering our understanding of the molecular events which trigger and subsequently sustain the neurodegenerative process. The data presented in this study represent the first steps in exploring the molecular neuropathology of these events in the human brain.

The results show that severe head trauma can be associated with deposition of $\beta \mathrm{AP}$ in the cortex of patients, some with very short survival times. Such deposits can occur in patients as young as 10 years of age and a comparison with the extent of $\beta \mathrm{AP}$ deposition in controls ${ }^{22}{ }^{23}$ indicates that the phenomenon is pathological and not an artefact of ageing. This finding is reinforced by the significantly increased rates of positivity for $\beta \mathrm{AP}$ deposition in our patients with head injury over 50 years of age compared with their age and sex matched controls (fig $2, \mathrm{p}<0.01$ ).

From the available clinical data we have attempted to determine which factors might be associated with $\beta \mathrm{AP}$ deposition. The statistical analyses suggest that cases of head injury with $\beta$ AP deposits are significantly more likely to have been injured in a fall than those without $(p<0.002)$. The incidence of $\beta A P$ deposition increases with age. Both fall-related injuries and age are associated with the presence of intracranial mass lesions and these factors are associated with increased mortality. ${ }^{30}$ The nature of the association between falls, age, and $\beta \mathrm{AP}$ deposition is unknown but is clearly of considerable interest in relation to the clinical outcome of the patient after a severe head injury. It should also be noted in this context that increasing age is by far the most significant risk factor for Alzheimer's disease. ${ }^{31} 32$

Increases in neuronal $\beta \mathrm{APP}$ immunoreactivity are readily detectable in patients with head injuries. No case was found to have $\beta$ AP deposition in the absence of increased $\beta$ APP immunoreactivity. This finding has since been confirmed in a further study. ${ }^{33}$ In the light of this we suggest that whereas $\beta \mathrm{AP}$ deposition is contingent on increased amounts of neuronal $\beta A P P$ it is by no means an inevitable consequence. Our findings indicate that this princi- ple holds true even in specific areas within an individual brain. This finding is less paradoxical than it seems as $\beta$ APP expression is regulated at the level of the single neuron. ${ }^{34}$ Thus a single injury may result in the differential regulation of $\beta \mathrm{APP}$, perhaps with differing time courses, even in neighbouring neurons.

In animals increased $\beta A P P$ immunoreactivity can be seen after experimental concussive head injury, ${ }^{35}$ ibotenic acid injection, ${ }^{36}$ and in other models of brain injury. ${ }^{37}$ This increase in $\beta$ APP immunoreactivity reflects either a reduced breakdown or an increased expression of the protein. Both processes may play a part and neither process can be categorically excluded but the available experimental evidence favours the second possibility. Increases in $\beta \mathrm{APP} \mathrm{mRNA}$ have been reported in reactive astrocytes after kainic acid induced neuronal damage. ${ }^{38}$ Furthermore it seems that there is a selective induction of $\beta A P P$ mRNA containing the Kunitz protease inhibitor domain ( $\beta$ APP 751/770) in the cortex of rats with middle cerebral artery occlusions ${ }^{39}$ and experimental models of epilepsy. ${ }^{40}$ The dominant $\beta$ APP mRNA species ( $\beta$ APP 695) remained unchanged in these animals. In axotomised animals $\beta \mathrm{APP}$ expression also increased in dorsal root ganglion cells. ${ }^{41}$

In humans $\beta \mathrm{APP}$ immunoreactivity accumulates within axonal swellings around cerebral infarcts ${ }^{42}$ and in situ hybridisation studies have shown that in Alzheimer's disease there is increased expression of the $\beta$ APP 751 transcript in cortical areas before the appearance of neuritic plaques and tangles..$^{43}$ Preliminary quantitative studies (unpublished) in humans indicate that after head injury, numbers of $\beta$ APP immunoreactive neurons are increased by over $500 \%$ compared with age and sex matched controls. Recent work on the metabolism of $\beta$ APP suggest that small amounts of the $\beta \mathrm{AP}$ amyloidogenic protein are produced during normal processing. ${ }^{44} 45$ These are important findings as they show that the occurrence of a de novo pathogenetic processing step is not a precondition for the production of $\beta \mathrm{AP}$ from $\beta \mathrm{APP}$. Such experimental studies strongly support the hypothesis that situations leading to increased $\beta$ APP expression provide sufficient potential for the subsequent pathogenesis of $\beta \mathrm{AP}$ deposition and subsequent Alzheimer's disease. ${ }^{29}$

Clearly the presence of $\beta \mathrm{AP}$ deposits in the cortex does not signify the full pathophysiological phenomenon of Alzheimer's disease. It is accepted, however, that Alzheimer's disease is a dynamic process that takes many years to manifest itself in the form recognisable by didactic clinical and pathological vignettes. It follows that Alzheimer's disease has early and late stages. This admittedly simplistic statement is worthwhile making as it allows us to reiterate that our study is concerned with the earliest stages of Alzheimer's disease.

There are at present no suitable animal models of Alzheimer's disease. The best model available for studying the molecular neuropathology of the early stages of the disease comes from a careful examination of 
the brains of patients with Down's syndrome (trisomy 21) most of whom have an additional copy of the $\beta$ APP gene. Extrapolation from such studies suggests that overexpression of $\beta$ APP over many years eventually triggers a pathological cascade that begins within the medial temporal lobe. This cascade manifests itself as increased $\beta \mathrm{APP}$ immunoreactivity in neurons and neurites, initial deposits of $\beta \mathrm{AP}$ in the form of diffuse plaques, and finally the formation of classic plaques and tangles. The full process may take some 30 years.

Our data show that the immediate effects of head injury (increased amounts of $\beta \mathrm{APP}$ in neurons and neurites and deposition of $\beta A P$ in diffuse deposits) are consistent with what we know about the earliest stages of Alzheimer's disease and support our contention that a study of such material might provide a useful model to dissect the molecular neuropathology of the initiating events in Alzheimer's disease.

The combined data from animal and human studies suggest that the induction of $\beta A P P \quad 751 / 770$ in the brain is a normal response to neuronal stress (analogous to a heat shock response) and as such increased expression of $\beta$ APP can be regarded as part of the acute phase response of the brain to injury. Sustained expression of the $\beta A P P$ component of the acute phase response might well be associated with an increased risk of the pathological deposition of $\beta \mathrm{AP}$ and subsequent neuritic dystrophy. ${ }^{27}{ }^{32}$ Differences in ability to maintain control of this response within the brain may underlie the presence of $\beta$ AP deposition in only $30 \%$ of patients with head injuries.

As $\beta$ APP overexpression and subsequent deposition is a critical part of both the acute phase response and the pathological process of Alzheimer's disease then it can be argued that manipulating the factors that control the acute phase response will affect $\beta$ APP expression and may influence the development of Alzheimer type pathology.21 46 Preliminary experiments in animals with a potent interluekin-1 receptor antagonist (recombinant version of a naturally occurring acute phase response inhibitor) indicate that this approach may be useful ${ }^{21}$ and clinical trials in humans indicate little or no adverse toxicology. ${ }^{47}$

Confocal microscopy in animals has shown that $\beta \mathrm{APP}$ is colocalised with synaptic vesicles and that the amount of $\beta$ APP found within a neuron might relate to its level of synpatic activity. ${ }^{34}$ Consequently alterations in $\beta$ APP metabolism might be expected to have profound effects on synaptic transmission. It can be speculated that the physiological role of $\beta$ APP during the acute phase response is to stabilise damaged synaptic membranes and thus enable synaptic plasticity and facilitate repair and regeneration. ${ }^{27}$ It is a neuropsychiatric irony that the normal, probably protective, response of increased $\beta$ APP expression could, if poorly controlled, metamorphose into the pathological processes of neurodegeneration and destruction that characterise Alzheimer's disease.
This work was funded by a Medical Research Council project grant and the Mental Health Foundation. SMG is an Alzheimer's Disease Society Research Fellow.

1 Anon editorial. Head injury victims in the UK: undeservedly underserved. Lancet $1990 ; \mathrm{i}: 886-7$.

2 Levin S, Benton AL, Grossman RG. Neurobehavioural consequences of closed head

3 Adams JH, Doyle D, Graham DI, et al. The contusion index: a reappraisal in human and experimental nonmissile head injury. Neuropathol Appl Neurobiol 1985; 11:299-308.

4 Adams JH, Doyle D, Ford I, Gennarelli TA, Graham DI, McLellan DR. Diffuse axonal injury in head injury: definitions, diagnosis and grading. Histopathology 1989;15: 49-59.

5 Graham DI, Ford I, Adams JH, et al. Ischaemic brain damage is still common in fatal non-missile head injury. $f$ Neurol Neurosurg Psychiatry 1989;52:346-50.

6 Adams JH, Graham DI. The relationship between ventricular fluid pressure and the neuropathology of raised intracranial pressure. Neuropathol Appl Neurobiol 1976;2: 323-32.

7 Roberts AJ. Brain damage in boxers. London: Pitman Medical Scientific, 1969.

8 Corsellis JAN, Bruton CJ, Freeman-Browne D. The aftermath of boxing. Psychol Med 1973;3:270-3.

9 Roberts GW, Allsop D, Bruton CJ. The occult aftermath of boxing. $\mathcal{F}$ Neurol Neurosurg Psychiatry 1990;53:373-8.

10 Dale GE, Leigh PN, Luthert P, Anderton BH, Roberts GW. Neurofibrillary tangles in dementia pugilistica are ubiquitinated. If Neurol Neurosurg Psychiatry 1991;54 $116-8$

11 Allsop D, Haga S, Bruton C, Ishii T, Roberts GW. Neurofibrillary tangles in some cases of dementia pugilistica share antigens with amyloid beta protein of Alzheimer's disease. Am F Pathol 1990;136:255-60.

12 Roberts GW. Immunocytochemistry of neurofibrillary tangles in dementia pugilistica and Alzheimer's disease: evidence for common genesis. Lancet 1988;ii:1456-8.

13 Clinton J, Ambler MW, Roberts GW. Post-traumatic Alzheimer's disease: preponderance of a single plaque Alzheimer's disease: preponderance of a single
type. Neuropathol Appl Neurobiol 1991;17:69-74.

14 Roberts GW, Whitwell HL, Acland PR, Bruton CJ. Dementia in a punch-drunk wife. Lancet 1990;i:918-9.

15 Roberts GW, Gentleman SM, Lynch A, Graham DI. $\beta$ A4 amyloid protein deposition in brain after head trauma. amyloid protein depositio

16 Amaducci LA, Fratiglioni L, Rocca WA, et al. Risk factors for clinically diagnosed Alzheimer's disease: a case control study in an Italian population. Neurology 1986;36 922-31

17 French LR, Schuman LM, Mortimer JA, Hutton JT, Boatman RA, Christians B. A case-control study of dementia of the Alzheimer type. Am $\mathcal{f}$ Epidemio 1985;121:414-21.

18 Mortimer JA, van Duijn CM, Chandra V, et al. Head injury as a risk factor for Alzheimer's disease: a collaborative re-analysis of case-control studies. Int $f$ Epidemiol 1991;20:S28.

19 Rudelli R, Strom JO, Welch PT, Ambler MW. Post-traumatic premature Alzheimer's disease: neuropathologic matic premature Alzheimer's disease: neuropathologic findings and par

20 Hardy J, Allsop D. Amyloid deposition as the central event in the aetiology of Alzheimer's disease. TIPS 1991, 12:383-8.

21 Royston MC, Rothwell NJ, Roberts GW. Alzheimer's disease: pathology to potential treatments? TIPS 1992;13 131-3.

22 Davies L, Wolska B, Hilbich C, et al. A4 amyloid protein deposition and the diagnosis of Alzheimer's disease: Prevalence in aged brains determined by immunocytochemistry compared with conventional neuropathologic techniques. Neurology 1988;38:1688-93.

23 Gentleman SM, Bruton CJ, Allsop D, Lewis SJ, Polak JM, Roberts GW. A demonstration of the advantages of immunostaining in the quantification of amyloid plaque immunostaining in the quantification of

24 Mirra SS, Heyman A, McKeel D, et al. The Consortium to Establish a Registry for Alzheimer's Disease (CERAD). Part II. Standardization of the neuropathologic assessment of Alzheimer's disease. Neurology logic assessment

25 Tomlinson BE. Ageing and the dementias. In Adams JH Duchen LW, eds. Greenfield's neuropathology, 5th ed. London: Edward Arnold, 1992;1284-410.

26 Hardy J. Framing $\beta$-amyloid. Nature Genetics 1992;1: $233-4$.

27 Gentleman SM, Graham DI, Roberts GW. Molecular pathology of head trauma: altered $\beta$ APP metabolism and the aetiology of Alzheimer's disease. Prog Brain Res 1993;96:237-46.

28 Gautrin D, Gauthier S. Alzheimer's disease: environmental factors and etiologic hypotheses. Can $\mathcal{f}$ Neurol $\mathrm{Sc}$ 1989;16:375-87.

29 Gentleman SM, Roberts GW. Risk factors in Alzheimer's disease. $B M \mathcal{F}$ 1991;304:118-9.

30 Shedden P, Moulton RJ, Sullivan I, Hotz G, Tucker WS Muller PJ. Effect of population characteristics on head Muller PJ. Effect of population characteristics

31 van Duijn CM, Stijnen T, Hofman A. Risk factors for 
Alzheimer's disease: Overview of the EURODEM collaborative re-analysis of case control studies. Int $f$ Epidemiol 1991;20(supp 2):S4-12.

32 Roberts GW, Nash M, Ince PJ, Royston MC, Gentleman SM. On the origin of Alzheimer's disease: An hypothesis. Neuroreport 1993;4:7-9.

33 Gentleman SM, Nash MJ, Sweeting CJ, Graham DI, Roberts GW. $\beta$-amyloid precursor protein $(\beta \mathrm{APP})$ as a marker for axonal injury after head injury. Neurosci Lett marker for axonal in

34 Schubert W, Prior $R$, Weidemann A, Dircksen $H$ Multhaup G, Masters CL, Beyreuther K. Localization of Alzheimer $\beta A 4$ amyloid precursor protein at central and peripheral synaptic sites. Brain Res 1991;563:184-94.

35 Games D, Khan KM, Soriano FG, Lieberburg I, Sinha S. Evidence for altered APP processing following acute head trauma in the rodent. [Abstract 601.2] Los Angeles: Society for Neuroscience, 1992.

36 Nakamura Y, Takeda M, Niigawa H, Hariguchi S, Nishimura T. Amyloid $\beta$-protein precursor deposition in rat hippocampus lesioned by ibotenic acid injection. Neurosci Lett 1992;136:95-8.

37 Kawarabayashi T, Shoji M, Harigaya Y, Yamaguchi $H$, Hirai S. Expression of APP in the early stages of brain Hainas. Brain Res 1991;563:334-8.

38 Siman R, Card JP, Nelson RB, Davis LG. Expression of $\beta$ amyloid precursor protein in reactive astrocytes followamyloid precursor protein in reactive astrocyte

39 Abe K, Tanzi RE, Kogure K. Selective induction of
Kunitz-type protease inhibitor domain-containing amyloid precursor protein mRNA after persistent focal ischaemia in rat cerebral cortex. Neurosci Lett 1991; 125:172-4.

40 Willoughby DA, Johnson SA, Pasinetti GM, et al. Amyloid precursor protein mRNA encoding the Kunitz protease inhibitor domain is increased by kainic acid-induced seizures in rat hippocampus. Exp Neurol 1992;118: 332-9.

41 Scott IN, Parhad IM, Clark AW. $\beta$-amyloid precursor protein gene is differentially expressed in axotomized sentein gene is differentially expressed in axotomized sen-

42 Ohgami T, Kitamoto T, Tateishi J. Alzheimer's amyloid precursor protein accumulates within axonal swellings in human brain lesions. Neurosci Lett 1992;136:75-8.

43 Barton A. Studies of gene expression in the central nervous system in relation to Alzheimer's disease. London: University of London, 1991. (PhD thesis.)

44 Seubert P, Vigo-Pelfrey C, Esch F, et al. Isolation and quantification of soluble Alzheimer's $\beta$-peptide from biological fluids. Nature 1992;359:325-7.

45 Shoji M, Golde TE, Ghiso J, et al. Production of the Alzheimer amyloid $\beta$ protein by normal proteolytic processing. Science 1992;258:126-9.

46 McGeer PL, Rogers J. Anti-inflammatory agents as a therapeutic approach to Alzheimer's disease. Neurology therapeutic app

47 Dinarello CA, Wolff SM. The role of interleukin-I in disease. N Engl F Med 1993;328:106-13. 